\title{
NEUTRON SCATTERING INSTRUMENTATION FOR MEASUREMENT OF MELT STRUCTURE
}

\author{
Phase II STTR Final Report \\ For Period September 1, 2002 - August 31, 2004
}

\begin{abstract}
J.K.R. Weber and C.J. Benmore*
Containerless Research, Inc. 906 University Place

Evanston, IL 60201

* Intense Pulsed Neutron Source

Argonne National Laboratory

Argonne, IL 60439
\end{abstract}

October 21, 2004

Prepared for

THE US DEPARTMENT OF ENERGY

Under Award No. DE-FG02-01ER86121 


\section{NOTICE}

This report was prepared as an account of work sponsored by the United States Government. Neither the United States nor the United States Department of Energy, nor any of their employees, nor any of their awardees, subcontractors, or their employees, makes any warranty, express or implied, or assumes any legal liability or responsibility for the accuracy, completeness, or usefulness of any information, apparatus, product or process disclosed or represents that its use would not infringe privately-owned rights.

\section{Preface}

This is the final technical report for research performed during the period September 1, 2002 to August 31, 2004 under Department of Energy Phase I I STTR Contract Number

DE-FG02-01ER86121 with Containerless Research, Inc. (CRI). Dr. Richard Weber of CRI was the Principal Investigator, assisted by Mr. James Rix, Mr. Scott Hampton, Dr. Jean Tangeman, Mr. Thomas Key, Mr. Richard Scheunemann and Ms. Kirsten Hiera of CRI.

Argonne National Laboratory (Intense Pulsed Neutron Source, IPNS) was the research institution partner and subcontractor in this STTR project. Research at IPNS was directed by Dr. Chris Benmore, assisted by Ms. Joan Siewenie, Dr. Robert Hart, Ms. Nicole Murphy, Dr. Quiang Mei, Mr. Ken Volin and Ms. Beverly Marzec.

We appreciate advice and suggestions from Mr. Lou Santodonato who leads the sample environment group at SNS and Dr. Chris Tulk of SNS. In addition we thank many scientists and engineers involved with the neutron scattering community who provided informal advice and suggestions either by direct contact or at technical meetings and seminars.

CONTAINERLESS RESEARCH, INC.

Signed

Richard Weber, $\mathrm{PhD}$

Vice President for Materials R\&D 


\section{Executive Summary}

This Phase II research project was focused on constructing and testing a facility for the measurement of the structure of hot solid and liquid materials under extreme conditions using neutron diffraction. The work resulted in measurements at temperatures of $3300 \mathrm{~K}$, the highest ever performed in a neutron beam. Work was performed jointly by Containerless Research, Inc. and Argonne National Laboratory with significant interactions with engineers and scientists at the under construction-SNS facility in Oak Ridge, TN. The work comprised four main activities:

- Design and construct an advanced instrument for structural studies of liquids and hot solids using neutron scattering.

- Develop and test a software package for instrument control, data acquisition and analysis.

- Test and demonstrate the instrument in experiments at the GLAD beamline at IPNS. Evaluate requirements for performing experiments at the SNS.

- Develop interest from the potential user base and identify potential support for Phase III.

The objectives of the research were met. A second-generation instrument was developed and constructed. The instrument design drew on the results of a formal design review which was held at Argonne National Laboratory during the Phase I research [1]. The review included discussion with potential instrument users, SNS scientists and engineers and various scientists involved with materials, glass, ceramics, and geological sciences.

The instrument combines aerodynamic levitation with pulsed neutron diffraction in a controlled atmosphere. An important innovation was the use of pure vanadium levitation nozzles that effectively eliminated contributions from the sample environment to the measured data. The instrument employed a $250 \mathrm{Watt} \mathrm{CO}_{2}$ laser that was configured for Class I laser operation. The use of Class I laser configuration meant that operators could work with the equipment with minimal restrictions and so concentrate on the research activities. Instrument control and data acquisition software was developed and implemented. As part of a larger initiative at IPNS, PCbased programs are being developed for acquisition and processing of neutron data. The PCbased beamline data handling system will enable compatibility with the levitator software.

The instrument was bench tested at CRI and operated in three campaigns at the GLAD beamline at IPNS. Samples approximately $3.5 \mathrm{~mm}$ in diameter were levitated for periods up to 6 hours and at temperatures up to $3300 \mathrm{~K}$. Structure factors were obtained for liquid oxide materials and hot solids. Details are given in this report and in published or submitted papers.

During the course of the Phase I and Phase II projects, technical presentations were made at the Materials Research Society meeting in Boston, November, 2001, the American Conference on Neutron Scattering in Knoxville, TN, June, 2002, the Gordon Research Conference on High Temperature Chemistry (poster) in Waterville, ME, August 2002, the ACNS meeting in Baltimore, MD, June, 2004 and the Non-crystalline Materials-9 meeting in Corning NY, July, 2004. Two manuscripts were prepared, one is published, one is in review. The presentations have resulted in contact with the user community and we have received several requests to use the instrument. As a result, we are seeking support for collaborative research and plan to offer beamline instruments for commercial sale. 


\section{Introduction}

Neutrons are an important tool for investigation of physical, chemical and biological phenomena [2-4]. There are currently 32 neutron facilities in operation throughout the world and seven more are under construction, the total number of beamlines exceeds 100 .

The goal of this project was to establish the basis for new instrumentation to expand the use of neutron measurements beyond their current limits by investigating the structure of molten materials, non-equilibrium liquids, and ultra-high temperature materials in-situ. The Phase I research demonstrated measurements of liquid structure at temperatures up to $2000 \mathrm{~K}$ by integrating an aerodynamic levitator with a $\mathrm{CO}_{2}$ heating laser and a neutron beamline. The Phase II research implemented an advanced levitator design capable of studying materials at temperatures over $3000 \mathrm{~K}$ in conditions that practically eliminate contributions to the data from the sample environment.

Liquids, and in particular molten materials are critical in value-added materials processing, energy production, geological processes, metallurgical refining, and they are of fundamental interest materials physics [5,6]. The structure of liquids and the structural changes which occur during solidification, the onset of glass formation and as the liquid viscosity changes with temperature are important in understanding and controlling material's behavior.

The combination of neutron techniques and containerless experimentation [7-9] enable advances in neutron instrumentation by: (i) elimination of interactions between the container and the molten sample - this is especially important when corrosive high temperature liquids or very hot solids are being handled, (ii) elimination of container-derived heterogeneous nucleation of liquids - this allows deep undercooling to access metastable liquids and novel glasses, and (iii) a reduced contribution by container scattering in the results.

Emerging high-flux beam lines such as spallation neutron sources provide a large accessible Q-range leading to high real space resolution. The new facilities can enable fast measurements of liquid structure during dynamic changes such as vitrification, crystallization and other processing operations which are key to the development and manufacture of advanced materials and to improved understanding of geological processes.

This report summarizes the research results.

Phase II Technical Objectives and Research Tasks:

The four Phase II technical objectives are presented below.

Task 1 - Design and construct an advanced instrument for studies of liquid structure under extreme conditions which incorporates features identified in the Phase I design analysis.

Task 2 - Develop and test software package for data acquisition and analysis. 
Task 3 - Demonstrate the instrument in experiments at the GLAD beamline at IPNS. Evaluate requirements for performing experiments in the Disordered Materials Diffractometer at SNS.

Task 4 - Develop the user base and support for Phase III research experiments.

The detailed work breakdown structure for the Phase II activities was presented in our Phase II proposal and workplan. The plan was implemented as proposed and the tasks were completed on schedule. The instrument design and construction was primarily performed by CRI. Special components to integrate the instrument with the GLAD beamline were constructed by the STTR partner, Argonne National Laboratory. Software for data acquisition and analysis was jointly developed by CRI (instrument) and IPNS (data analysis). The instrument was tested at the GLAD beamline.

The main elements of the work plan are briefly summarized below.

\section{Construct Instrument}

The Phase II instrument was designed to incorporate features identified during the Phase I research. The following features were considered to be of high value to a user and provide a versatile instrument for advanced materials research at a neutron beamline:

1. Easy installation/deinstallation at a beamline user facility.

2. Easy calibration, sample exchange/recovery, nozzle exchange and maintenance.

3. Ability to investigate samples in a controlled environments, e.g. $\mathrm{O}_{2}, \mathrm{~N}_{2}$, inert, redox.

4. Adequate laser heating power to reach temperatures $>2500 \mathrm{~K}$.

5. Ability to obtain "rough" G(r) quickly in order to plan ongoing experiments.

6. Class I laser system (with embedded Class IV laser) to minimize user training requirements.

7. Small "footprint" for hardware and ancillary equipment.

8. Remote monitoring and control of system operations.

Additional qualities of a user facility considered desirable were: (i) availability of a bench top instrument for sample characterization/glass synthesis, (ii) the ability to perform fast measurements $(<1$ hour $)$ to enable studies of temperature-dependence and transient effects, and (iii) a complementary instrument for X-ray studies on liquids.

The general layout of the facility is illustrated in Fig. 1. Photographs of the facility are shown in Fig. 2 and the levitation nozzles are shown in Fig. 3. The main structure of the instrument was made from Parker "Parframe" that was custom cut to allow construction of a stable housing for the laser and for the instrument components. The re-entrant well fabricated from aluminum alloy in the shops at Argonne and helium leak tested prior to use. An important design feature of the well was the small diameter housing in which the levitator components were mounted. The small housing reduced the neutron beam path length to approximately $10 \mathrm{~cm}$ in the low pressure levitation gas to reduce scattering by the gas. The re-entrant well was designed to interface with the GLAD beamline and it located the levitation position close to the height of the neutron beam. Instrument for use at other beamlines would require wells that are configured for the specific dimensions and arrangement of the beamline. 


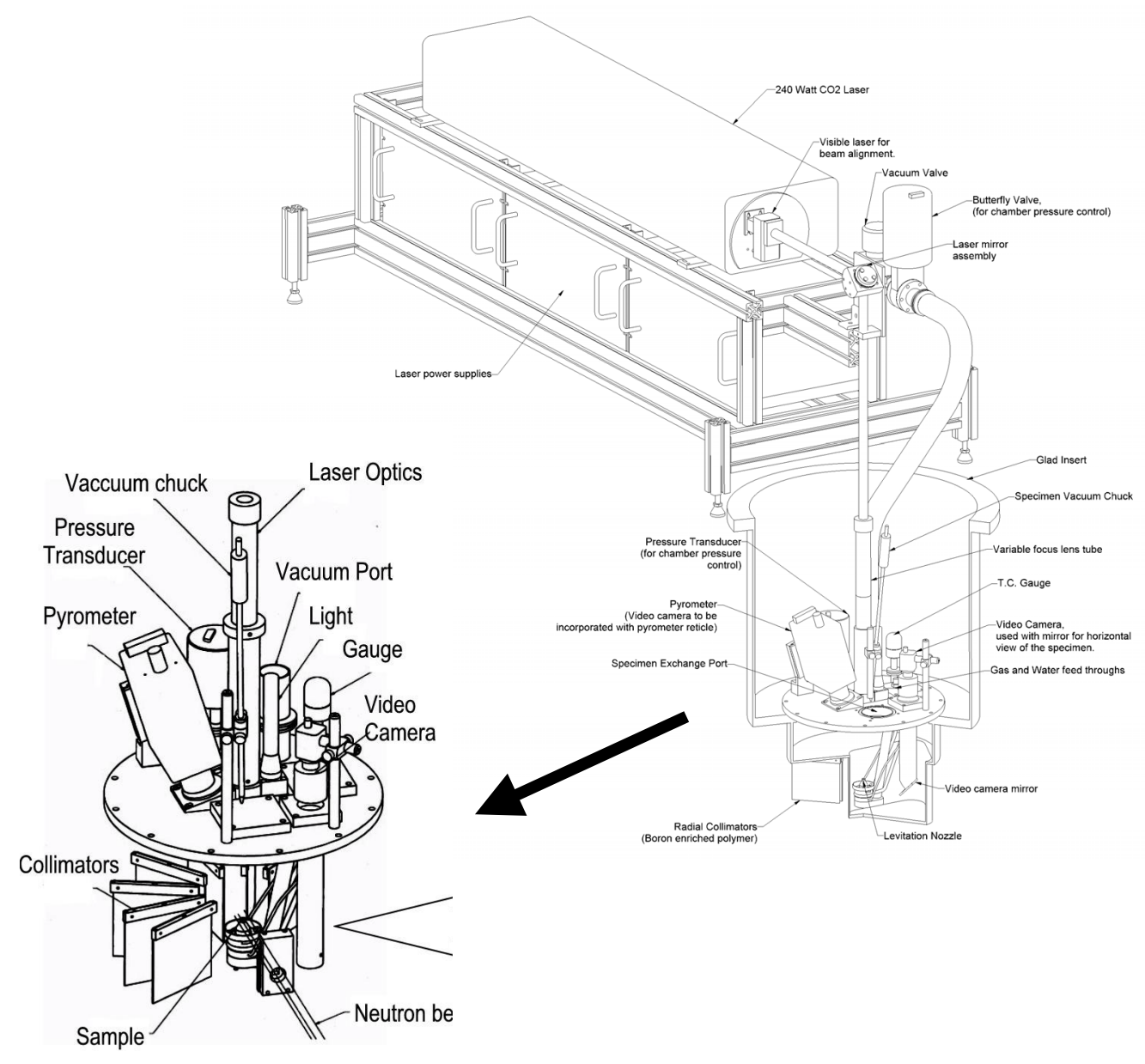

Fig. 1. Diagram showing the general layout of the main components of the instrument for investigation of hot solids and liquids at a neutron beamline. The inset to the left shows details of the boron-doped polymer collimators.

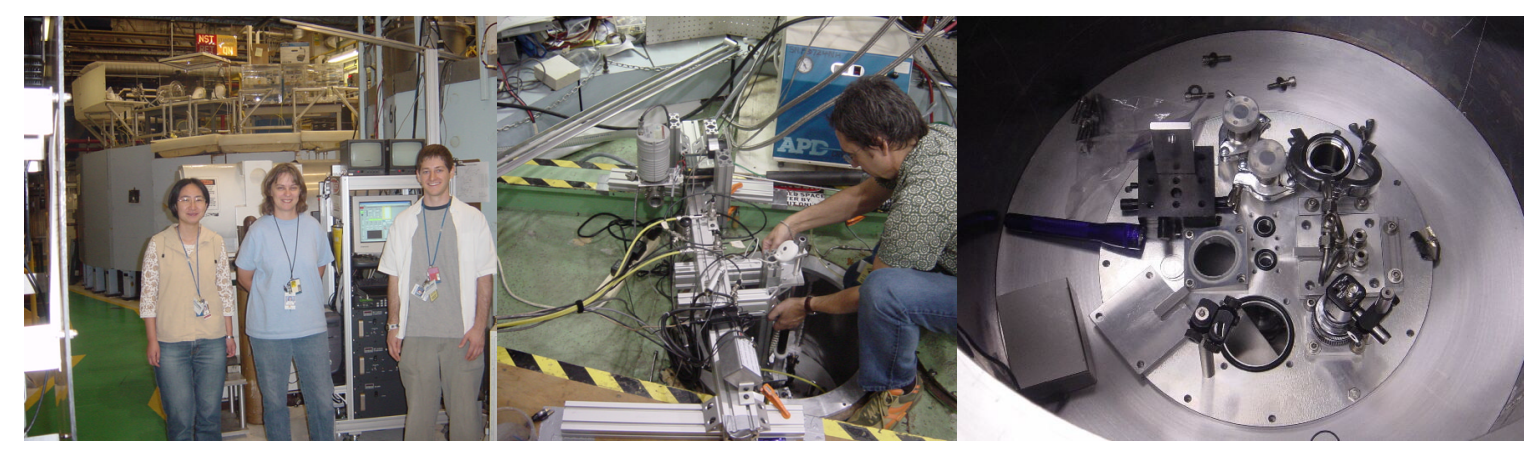

Fig. 2. From left: Quiang Mei, Joan Siewenie and Richard Scheunemann next to the instrument control panel at GLAD; Jim Rix installing the laser beam steering assembly mounted on the top of the re-entrant well at GLAD; close up view of the insert that houses the levitator and feedthroughs for coolant, gas and vacuum lines. 


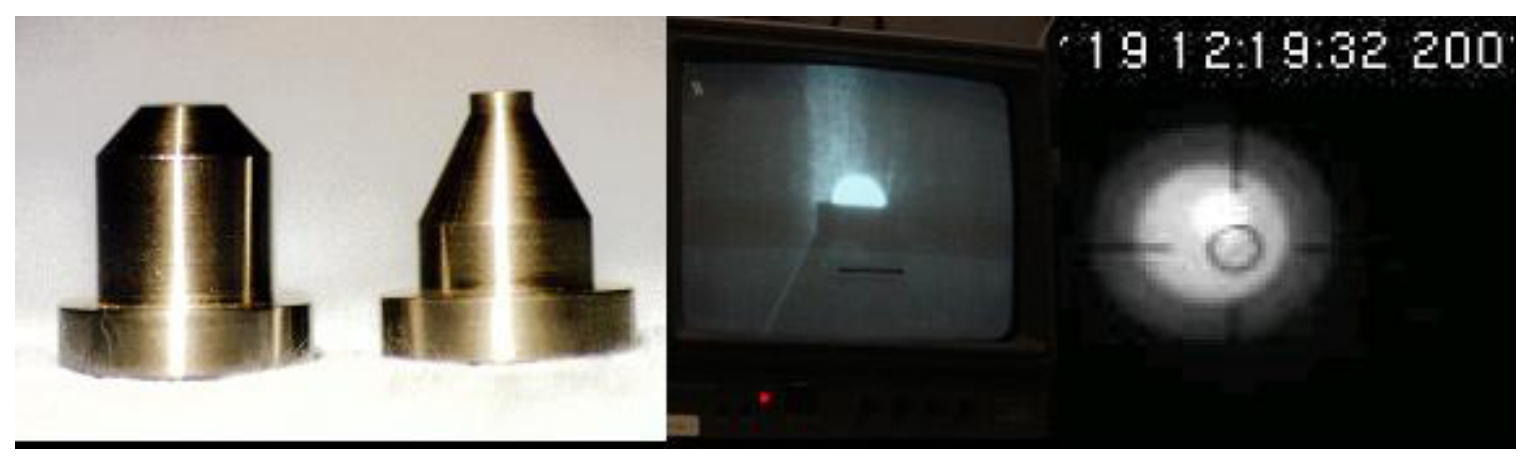

Fig. 3. Left - thick- and thin-walled vanadium levitation nozzles; center - image of a levitated sample viewed from the side; right - view of a levitated liquid sample viewed from a video camera that images through the optical pyrometer used to measure the sample temperature.

\section{Develop software package}

The flow chart illustrating the data analysis software approach is shown in Fig. 4.

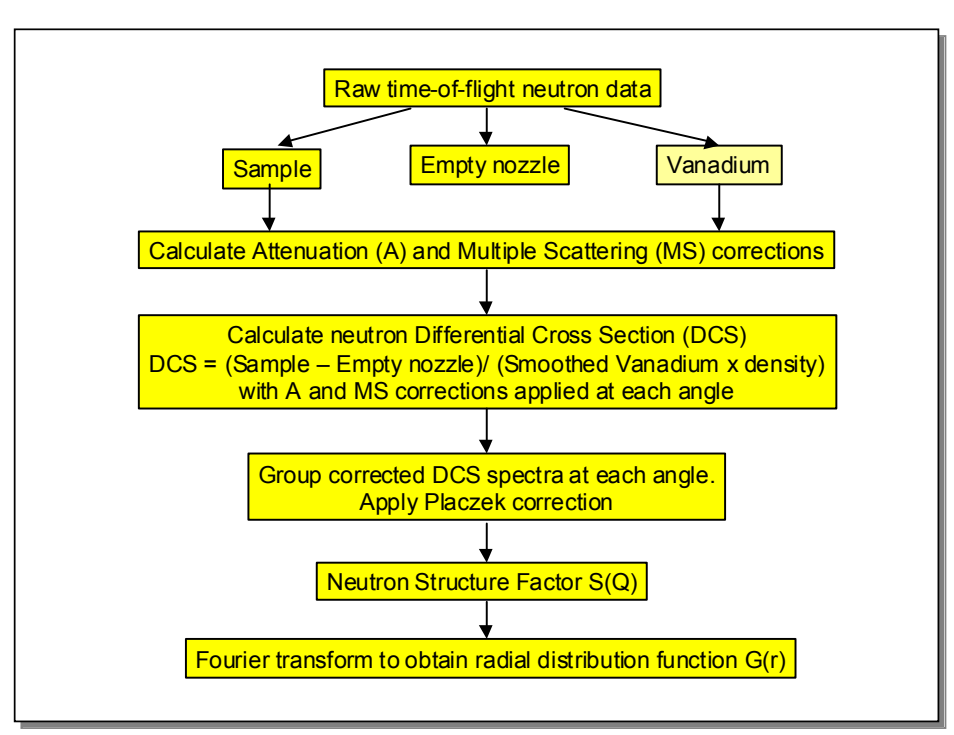

Fig. 4. Flowchart of data analysis procedure for containerless measurements. A smoothing algorithm was developed and applied to the data in order to reduce the noise in the data.

Raw neutron data were collected and then corrected for contributions from the levitation nozzle, background, inelastic and multiple scattering. The "raw" structure factor was then obtained from the corrected data.

The instrument was controlled using a software control and acquisition package written in LabView. The program was used to control the levitation parameters - total chamber pressure and levitation gas flow rate, control laser power, heating rate and cool down rate, and monitor and acquire the output from an optical pyrometer that measured the sample temperature. A video signal was also acquired by computer. 


\section{Instrument testing at IPNS}

The Phase II instrument was integrated into the GLAD beamline at IPNS (see Figs 1-3 above). Experiments were performed on a variety of materials as summarized below. Detailed results have been submitted for publication [10,11]. Preliminary results were written up as a success story for DOE in a bulletin format in July, 2003. Levitation of hot solids and liquids was achieved at a pressure of approximately 0.5 bar using a gas flow rate of $\sim 8 \mathrm{~cm}^{3} / \mathrm{s}(500$ standard cubic centimeters per minute). Liquid samples were levitated for periods of up to 6 hours. Total data acquisition times were up to 22 hours for the calcium aluminate composition, obtained using four different samples replaced at $\sim 6$ hour intervals. Measurements on liquid $\mathrm{YAG}$ and $\mathrm{ZrO}_{2}$ were limited to approximately 2 hours each. Mass losses from the low vapor pressure samples were negligible. Progress of the experiments was followed with a video camera and pyrometer focused on the sample.

\section{Results}

Results of the structure measurements on the calcium aluminate, YAG, and zirconium dioxide are presented in Figs. 5-10. Results of X-ray measurements are also shown in Figs. 5 and 6 [12]. The data for molten YAG and $\mathrm{ZrO}_{2}$ showed no evidence of Bragg peaks. The short duration of the experiments on the molten $\mathrm{YAG}$ and $\mathrm{ZrO}_{2}$ samples resulted in noisy data.

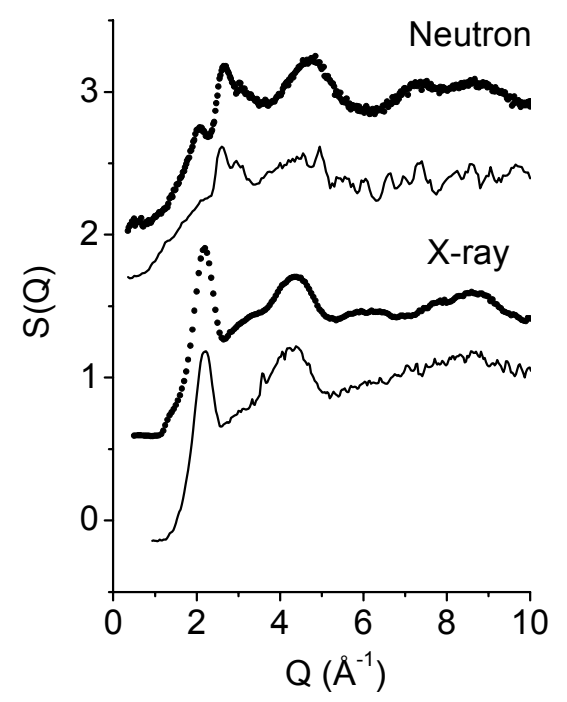

Fig 5. Measured neutron and $\mathrm{x}$-ray structure factors for $\mathrm{CaO}-\mathrm{Al}_{2} \mathrm{O}_{3}(64: 36)$ eutectic composition liquid (lines) and glasses (circles) (see also refs. 12,13). 


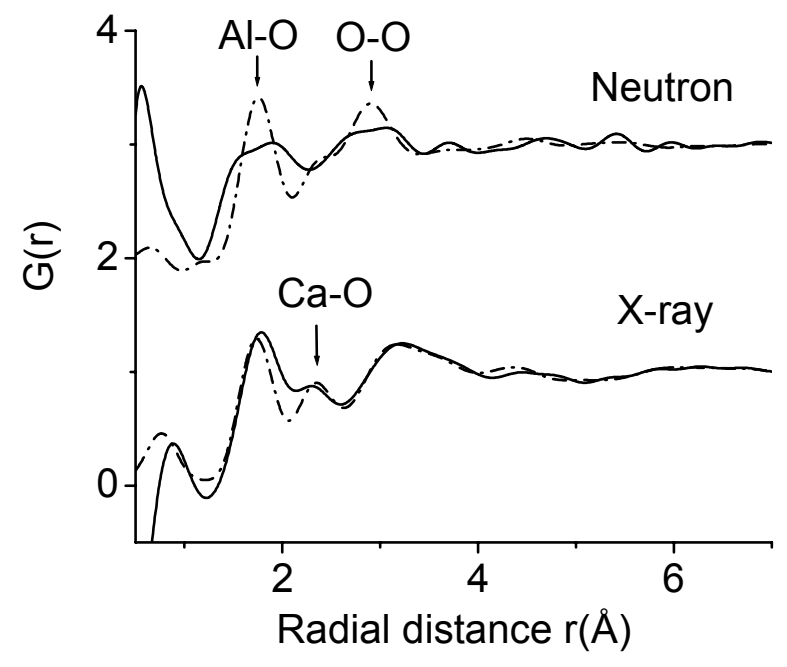

Fig 6. Neutron and $\mathrm{x}$-ray radial distribution functions for the $\mathrm{CaO}-\mathrm{Al}_{2} \mathrm{O}_{3}$ eutectic composition liquid (solid lines) and glasses (dashed lines) truncated at $\mathrm{Q}_{\max }=15 \AA^{-1}$ with a Lorch modification function. Both the neutron and $\mathrm{x}$-ray data indicate that higher coordinate Al-O species are present in the liquid compared to the glass. This is also reflected in the broadening of the O-O peak in the neutron spectra for the liquid.

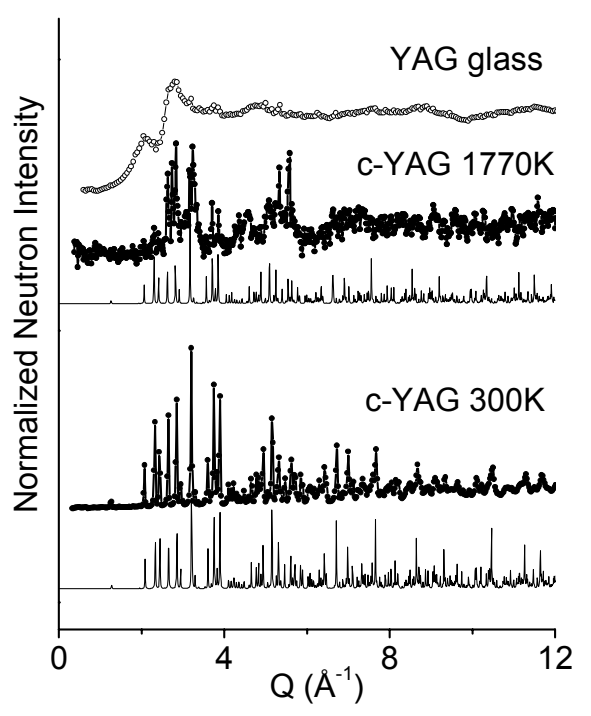

Fig 7. Comparison of neutron spectra for hot and cold crystalline YAG (lines and solid circles) and glassy YAG (open circles, top). The Rietveld refinements of the crystal data are shown as thin lines at $300 \mathrm{~K}$ (bottom) and $1770 \mathrm{~K}$ (middle). A spurious background peak at $\mathrm{Q}=4.5 \AA^{-1}$ has been removed from the $1770 \mathrm{~K}$ data. We note that the measured $1770 \mathrm{~K}$ data has a considerable amount of diffuse scatter in addition to the crystalline component. The derived lattice parameters are 12.02 and $12.21 \AA$ at $300 \mathrm{~K}$ and $1770 \mathrm{~K}$ respectively. 


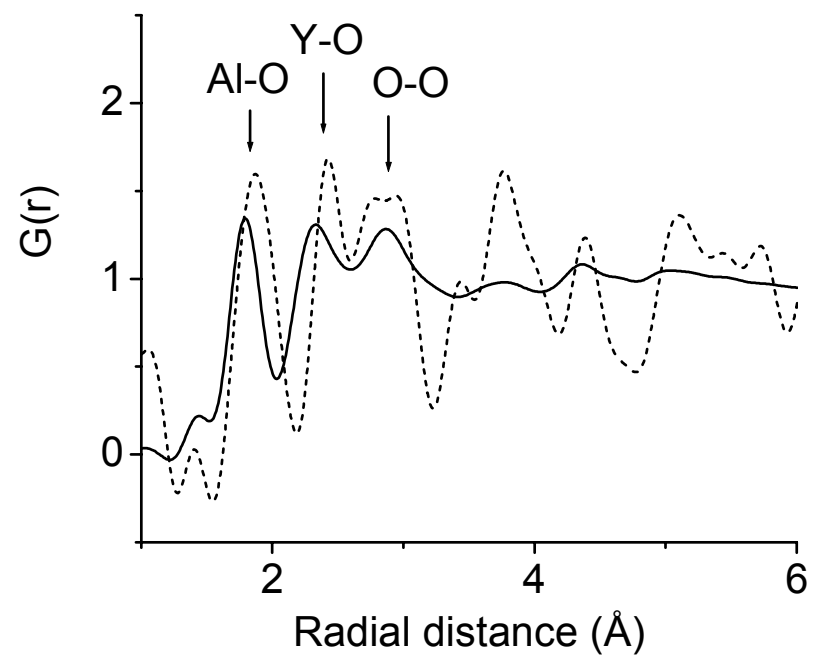

Fig 8. Comparison of neutron radial distribution functions for the crystalline YAG fit to the data at $1770 \mathrm{~K}$ (dashed line) and ambient temperature glass (solid line) [14]. The Q-space data sets (shown in figure 6) were both Fourier transformed from $\mathrm{Q}_{\max }=25 \AA^{-1}$ using a Lorch modification function using densities of 0.080 atoms $\AA^{-3}$ (glass) and 0.08776 atoms $\AA^{-3}$ (crystal).

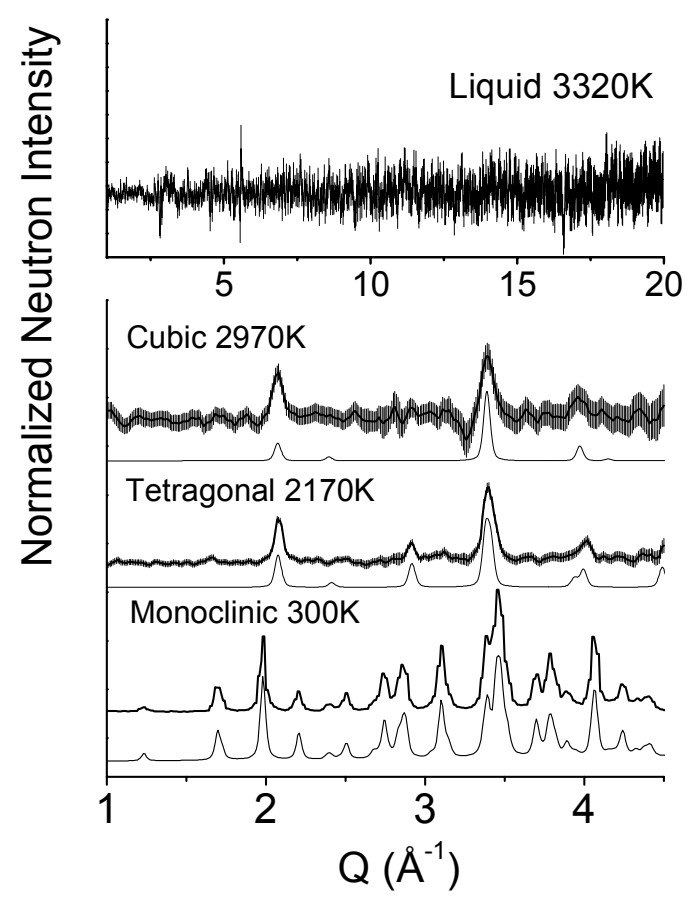

Fig. 9 Neutron spectra for $\mathrm{ZrO}_{2}$ monoclinic, tetragonal and cubic crystal phases (bottom plot) and liquid (top plot). The data for the crystalline phases are shown with errorbars and Rietveld fits to the data are given below. The data for the liquid collected over 30 minutes demonstrate the excellent instrument and levitator stability over a wide range of momentum transfer even at very high temperatures. 


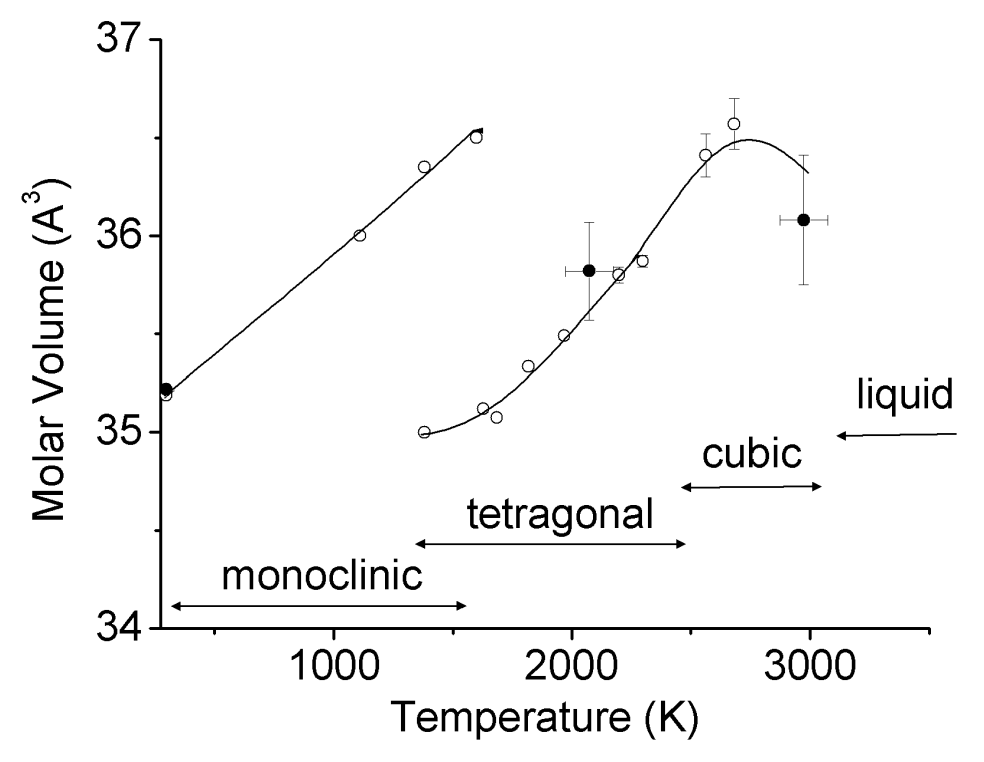

Fig. 10. Molar volume of $\mathrm{ZrO}_{2}$ from measurements on levitated samples (solid circles) with data from the literature [15-17] inserted for comparison (open circles). Note the apparent decrease in molar volume (i.e., increase in density) at very high temperature.

\section{Discussion}

1. Levitation experiments - Aerodynamic levitation utilizes a very compact and versatile levitation technology that can be integrated with beamlines. The small levitator footprint and the use of vanadium nozzles practically eliminated the effects of the sample "holder" from the interpretation of the experimental data. The use of uniaxial laser beam heating resulted in temperature gradients due to cooling of the underside of the sample by the levitation gas flow. In the case of low viscosity liquids, stirring of the melt by convection effectively distributes heat and decreases gradients to tens of degrees in a $3 \mathrm{~mm}$ diameter drop. Test experiments at CRI and at the Advanced Photon Source have shown that a second laser beam can be introduced through the underside of the nozzle via the nozzle orifice [18]. The use of underside heating reduces temperature gradients. Further work to optimize two-sided beam heating would expand the range of experiments that can be performed.

The levitation instrument was designed to be integrated with the GLAD beamline. With modifications to the re-entrant well and some ancillary components, the device can also be integrated with beamlines such as the NOMAD instrument that is being constructed at SNS. Ultimately, the high flux beamlines can extend the scientific capabilities of a levitation instrument by enabling fast measurements. Such measurements are necessary to investigate subtle temperature- and composition-dependent effects in fragile liquids, near the approach to the glass transition, or during nucleation of metastable phases.

2. Calcium oxide-aluminum oxide binaries - Calcium aluminate (CA) based glasses are potentially useful as infrared and laser host materials. CA glasses have been studied by Poe, et al. [19], Hannon and Parker [20], and Benmore, et al. [13]. In an earlier study by Benmore, et al. [13], the average the average aluminum ion coordination was determined to be 4.8. Based on 
the present work, we conclude that in the melt, the aluminum coordination increases compared to the glass. This result leads to a higher average aluminum coordination in the melt than was predicted by Poe, et al. [19]. The average Ca-O coordination in the 64C36A-composition glass was 5.6 [13]. In the liquid, the $\mathrm{Ca}-\mathrm{O}$ correlations are not clearly resolved but interpretation of the of O-O interactions at intermediate range r-values 4.5-5.5 $\AA$ are consistent with 6- and higher coordination. It appears that the coordination polyhedra in the liquid differ from those present in the glass and there is increased disorder arising from changes in connectivity of the polyhedra.

3. $Y A G-$ Measurements were made on solid polycrystalline YAG at temperatures of up to $\sim 1800$ $\mathrm{K}$ and YAG-composition glass at room temperature. A limited amount of data were obtained on liquid at $c a .2300 \mathrm{~K}$. The results of the Rietveld refinements of the data on solid samples are shown in Fig. 7. The lattice parameter increases from 12.02 to $12.21 \AA$ over the temperature interval 300 to $1770 \mathrm{~K}$. The calculated average thermal expansion coefficient is $10 \times 10^{-6} / \mathrm{K}$ over this temperature interval. The value of expansion coefficient agrees with literature data of $9 \mathrm{x}$ $10^{-6} / \mathrm{K}[21]$.

The neutron radial distribution functions for crystalline YAG at $1770 \mathrm{~K}$ and YAG-composition glass [14] at room temperature are compared in Fig. 8. The data show that average Al-O bond length is $1.87 \AA$ in the hot crystal and 1.79(1) $\AA$ in the glass, and the Y-O average bond length is $2.42 \AA$ (crystal) to $2.33(1) \AA$ (glass). These changes in bond lengths indicate that both Al and Y are in lower coordinate in the glass than in the equilibrium crystal.

Analysis of the diffraction data showed no evidence of alumina or yttrium aluminum perovskite phases. In addition, thermodynamic measurements on $\mathrm{YAG}$, vitreous $\mathrm{Y}_{3} \mathrm{Al}_{5} \mathrm{O}_{12}$, and a mixture of yttrium aluminum perovskite and alumina of equivalent composition to YAG, showed that the garnet phase is the most stable. The in-situ neutron scattering measurements confirm that the garnet phase is stable to at least $1770 \mathrm{~K}$, or approximately $80 \%$ of the absolute melting point of crystalline YAG.

4. Zirconium Dioxide - When $\mathrm{ZrO}_{2}$ was heated, three crystalline polymorphs, monoclinic, tetragonal, and cubic were observed with increasing temperature (see Fig. 7). The refined structures agree well with literature data [15-17] to $\sim 1800 \mathrm{~K}$ (see Fig. 9). The very high temperature cubic phase observed at $c a .3000 \mathrm{~K}$ has a higher density, $\sim 1.5 \%$ larger, than predicted from extrapolation of data obtained by Aldebert and Traverse [15] and Frey, et al. $[16,17]$. The increase in density may indicate that a "pre-melting" effect occurs in $\mathrm{ZrO}_{2}$ at temperatures close to the melting point. This effect may be due in part to changes in metal:oxygen stoichiometry that zirconia is known to display. The experiments were performed in argon. Additional experiments in oxygen and perhaps at intermediate $\mathrm{p}\left(\mathrm{O}_{2}\right)$ would help to elucidate the mechanism of the density change.

\section{Conclusions}

1. The feasibility of combining a levitation instrument with a neutron beamline and obtaining neutron structure factors on solids and liquids over the temperature range 300-3300 K was demonstrated. The use of pure vanadium nozzles practically eliminated scattering contributions from the sample "holder". 
2. The total neutron structure factors, $\mathrm{S}_{\mathrm{N}}(\mathrm{Q})$, were obtained for $64: 36$ mole $\% \mathrm{CaO}: \mathrm{Al}_{2} \mathrm{O}_{3}$ composition liquids at $c a$. $2000 \mathrm{~K}, \mathrm{YAG}$ at $300-2300 \mathrm{~K}$ and $\mathrm{ZrO}_{2}$ at $300-3300 \mathrm{~K}$.

3. In the $\mathrm{CA}$ liquid, both $\mathrm{Al}$ and $\mathrm{Ca}$ ions are in a higher coordination with oxygen than in the corresponding glass. The thermal expansion coefficient of crystalline YAG was calculated to be $10 \times 10^{-6} / \mathrm{K}$ in the temperature interval $300-1800 \mathrm{~K}$. The average coordination of the $\mathrm{Al}$ and $\mathrm{Y}$ ions in the glass was lower than in the equilibrium crystal. The $\mathrm{ZrO}_{2}$ showed three crystalline polymorphs when it was heated. The density of the solid $\mathrm{ZrO}_{2}$ at $c a .3000 \mathrm{~K}$ is slightly higher than the literature predicts.

4. The ability to perform rapid neutron diffraction measurements on materials at extreme temperatures will enable detailed investigation of the structure of metastable and liquid materials.

5. The primary commercial market for the instrumentation is beamlines engaged in studying the structure of disordered materials using non-contact probes - primarily neutrons and X-rays. Additional markets are in development of new non-equilibrium materials.

\section{References}

1. J.K.R. Weber, J.E. Rix, C.J. Benmore and J.E. Siewenie. Preliminary Design Review, Neutron Scattering Instrumentation for Measurement of Melt Structure, Argonne National Laboratory, March, 12, 2002.

2 Materials Research Society Symposium: Emerging Applications of Neutron Scattering in Materials Science, L. Horton, organizer, Boston, MA, Nov. 26-30 (2001).

3. Workshop proceedings, "Novel Materials for Extreme Environments, A Vision for a Neutron Instrument for Materials Research Under Extreme Environments," C.K. Loong, Ed., IPNS 11-12 Sep., 1998.

4. See for example: Methods in Experimental Physics, Chapter 14. Classical Fluids, P.A. Egelstaff. Vol 23. Part B 1987. "Radiation Scattering Experiments on Fluids" in Molecular Liquids: New Perspectives in Physics and Chemistry, 1992, P.A. Egelstaff, editor J.J.C.Teixeira-Dias.

5. See for example: A. Navrotsky, Physics and Chemistry of Earth Minerals, Cambridge Univ. Press, 1998.

6. See for example: J.E. Enderby, D.M. North and P.A. Egelstaff, Phil. Mag. 14, 961 (1966). An Introduction to the Liquid State, P.A. Egelstaff, First ed. Academic Press 1967, Second Edition Oxford University Press 1992.

7. J.K.R. Weber and P.C. Nordine, "Containerless Liquid-Phase Processing at High Temperatures," Microgravity Science and Technology, VII, 279-282 (1995). 
8. S. Krishnan, J.J. Felten, J.E. Rix, J.K.R. Weber, P.C. Nordine, M.A. Beno, S. Ansell and D.L. Price, "Levitation Apparatus for Structural Studies of High Temperature Liquids Using Synchrotron Radiation," Rev. Sci. Instrum., 68, 3512-3518 (1997).

9. C. Landron, L. Hennet, J.-P. Coutures, T.E. Jenkins, C. Aletru, G.N. Greaves, A.K. Soper and G. Derbyshire, Aerodynamic Laser-heated Contactless Furnace for Neutron Scattering Experiments at Elevated Temperatures, Rev. Sci. Instrum., 71, 1745 (2000).

10. J.K.R. Weber, C.J. Benmore, J.A. Tangeman, J. Siewenie and K.J. Hiera, "Structure of Binary $\mathrm{CaO}-\mathrm{Al}_{2} \mathrm{O}_{3}$ and $\mathrm{SrO}-\mathrm{Al}_{2} \mathrm{O}_{3}$ Liquids by Combined Levitation-Neutron Diffraction," J. Neutron Res., 11, 113-21 (2003).

11. J.K.R. Weber, J.E. Rix, K.J. Hiera, J.A. Tangeman, C.J. Benmore, R.T. Hart, J.E. Siewenie and L.J. Santodonato, "Neutron Diffraction from Levitated Liquids -- a Technique for Measurements under Extreme Conditions", Phys. Chem. Glass, sub.

12. Hennet and S. Krishnan, private communication.

13. C.J. Benmore, J.K.R. Weber, J. Siewenie, J. Urquidi, J.A. Tangeman and S. Sampath, "A Structural Study of the Glassy $\mathrm{CaO}-\mathrm{Al}_{2} \mathrm{O}_{3}$ Eutectic," J. Phys. Cond. Matt., 15, 2413-2423 (2003).

14. J.K.R. Weber, C.J. Benmore, J. Urquidi, J. Siewenie, and T.S. Key, "Structure and Polyamorphism in Alumina-based Glasses,” Phys. Chem. Chem. Phys., 6, 2480-83, (2004).

15. P. Aldebert and J.P. Traverse, "Structure and Ionic Mobility of Zirconia at High Temperature," J. Am. Ceram. Soc., 68, 34 (1985).

16. F. Frey, H. Boysen and T. Vogt, "Neutron Powder Investigation of the Tetragonal to Monoclinic Phase Transformation in Undoped Zirconia," Acta Cryst., 46B, 724 (1990).

17. H. Boysen, F. Frey and T. Vogt, "Neutron Powder Investigation of the Monoclinic to Tetragonal Phase Transformation in Undoped Zirconia, Acta Cryst., 47B, 881 (1991).

18. CRI, unpublished research.

19. B.T. Poe, P.F. McMillan, B.Cote, D., Massiot, and J.-P. Coutures, "Magnesium and Calcium Aluminate Liquids: in situ High-temperature ${ }^{27}$ Al NMR Spectroscopy", Science, 259, 786 (1993).

20. A.C. Hannon and J.M. Parker, "The Structure of Aluminate Glasses by Neutron Diffraction,” J. Non-cryst. Solids, 274, 102-9 (2000). 
21. S. Geller, G.P. Espinosa, and P.B. Crandell, "Thermal Expansion of Y, Gd, Fe, Ga, and Al Garnets," J. Appl. Cryst., 2, 86 (1969). 